\title{
ALLIANCE PORTFOLIO DIVERSITY AND DOMINANT LOGIC THEORY
}

\author{
Dr. Christopher Penney \\ University of North Texas • Denton, TX
}

\section{ABSTRACT}

Alliance portfolio diversity has emerged as a topic of considerable research interest. Two central questions remain: why are some firms are better at managing alliance portfolio diversity than others, and does the form of alliance portfolio diversity matter? I develop a framework using dominant logic theory to explore these questions. I distinguish related alliance portfolio diversity from unrelated alliance portfolio diversity, and argue that when a firm engages in related alliance portfolio diversity strategy that matches its dominant logic(s), it will experience greater performance. I expect that firms lacking a prominent dominant logic will engage in unrelated alliance portfolio diversity. I also argue that if firms engage in related alliance portfolio diversity in an area(s) that does not match its dominant logic(s), there will be a mismatch, triggering a reduction in firm performance and the development of a new dominant logic. Finally, I offer directions for future research.

\section{INTRODUCTION}

Today's firms cannot "go it alone (Lee, Kirkpatrick-Husk, \& Madhavan, 2017)." On the contrary, managers must competently manage a greater number of alliances than ever before (Kale \& Singh, 2009). Thus, a focus on alliance portfolios, defined as a firm's ongoing set of alliances (Ozcan \& Eisenhardt, 2009; Das \& Teng, 2000; Hoffmann, 2005; 2007; Wassmer, 2010), is important. Indeed, a firm's alliance portfolio is likely to be more crucial to firm performance than any individual alliance (Ozcan \& Eisenhardt, 2009). In the past decade, research attention in alliance portfolios has increased, resulting in two literature reviews (i.e., Kale \& Singh, 2009; Wassmer, 2010) and a meta-analysis (i.e., Lee et al., 2017).

Recent work has begun to explore how alliance portfolio managers configure their portfolios in ways that lead to greater performance (e.g., Lee et al., 2017; Wassmer, 2010). A key descriptor of alliance portfolio configuration is alliance portfolio diversity (Lee et al., 2014; Wuyts \& Dutta, 2014), which refers to the degree of variance in alliance partners in terms of resources, capabilities, knowledge, and technology (Goerzen \& Beamish, 2005; Jiang, Tao, \& Santoro, 2010; Lee et al., 2014). Alliance portfolio diversity offers managers several key benefits, including 
access to greater resources, capabilities, and information (Baum, Calabrese \& Silverman, 2000; Dussauge, Garrette, \& Mitchell, 2000; Lee et al., 2017). Most importantly, alliance portfolio diversity offers the potential to generate knowledge (Dussauge et al., 2000; Wuyts \& Dutta, 2014), which may be used to stimulate firm innovativeness (Baum et al., 2000; Cui \& O'Connor, 2012). Thus, in theory, it is more beneficial to form a smaller set of alliances with diverse partners than it is to form a larger set of alliances with less diverse partners (Lee et al., 2014).

In practice, however, the many costs involved with alliance portfolio diversity may outweigh their benefits (Goerzen, 2007; Lee et al., 2014). Indeed, as alliance portfolio diversity increases, it becomes more difficult to manage and coordinate across each partner (Bamford \& Ernst, 2002; Goerzen \& Beamish, 2005; Lee et al., 2014). Alliance portfolio diversity makes management costlier, in turn, because managers must juggle different firms" "vocabularies, paradigms, and even objectives" (Goerzen \& Beamish, 2005). As the focal firm's ability to coordinate and manage its portfolio is compromised, partners may reduce trust levels (Lee et al., 2014), requiring greater monitoring costs (Goerzen \& Beamish, 2005). Specific types of diversity may be even costlier. For example, geographic diversity may involve countries that are unable to resolve conflicts (Lee et al., 2014), whereas industry diversity may involve resource misfits or a lack of synergies between partners (Jiang et al., 2010). Ultimately, these problems may adversely affect firm performance (e.g., Goerzen \& Beamish, 2015; Lee et al., 2017).

Presently, the relationship between alliance portfolio diversity and performance remains elusive (Lee, Kirkpatrick-Husk, and Madhaven, 2017; Wuyts $\&$ Dutta, 2014). The literature has begun to realize that not all firms benefit from alliance portfolio diversity (Wuyts \& Dutta, 2014), and it appears that some managers are better able to reduce the costs of, and in turn benefit more from, alliance portfolio diversity (e.g., Jiang et al., 2010; Lee et al., 2017). Therefore, there is a need to consider why some firms can better manage alliance portfolio diversity than others, and if the particular form of alliance portfolio diversity matters (Lee et al., 2017). To help explore these important research questions, it is warranted to consider what we know about firm diversification, and use that knowledge to inform an investigation of alliance portfolio diversity ${ }^{1}$. Once we can better understand how managers approach alliance portfolio diversity, we can begin to untangle the relationship between alliance portfolio diversity and firm performance.

\footnotetext{
${ }^{1}$ Throughout this paper, the terms "diversity" and "diversification" are used interchangeably. Following the literature's prevailing nomenclature and to avoid confusion, the sooner is used for the alliance portfolio level and the latter is reserved for the firm level.
} 
There are many parallels between alliance portfolio diversity and firm diversification. In the 1980s, the relationship between firm-level diversification and performance was also described as elusive (Grant, 1996; Prahalad \& Bettis, 1986). The firm diversification literature was able to resolve some of the tension after Prahalad and Bettis (1986) developed the concept of a dominant logic. Dominant logic is a theory of corporate level management that deals with the influence of key executives and their abilities to manage diversified firms, and ultimately improve performance. Prahalad and Bettis (1986:490) define a dominant logic as "the way in which managers conceptualize the business and make critical resource allocation decisions." Consequently, a dominant logic "can allow a diversified firm to develop a framework that guides its different business units without becoming involved in each of their specific strategic decisions (Lampeel \& Shamsie, 2000:593)." Thus, dominant logic theory became central to the understanding of the relationship between firm diversification and performance (Grant, 1988).

In more recent years, dominant logic theory has been expanded to apply to virtually any decision made throughout the firm, owing to a shared mind-set and world view (Lampel \& Shamsie, 2000). Prior to the development of dominant logic theory to explain why managers can more effectively manage certain types of firmlevel diversification, the literature lacked theory to connect firm diversification to performance. Thus, in this paper I extend dominant logic theory into the alliance portfolio diversity context. In doing so, I explain why some firms are more (less) likely to benefit from certain forms of alliance portfolio diversity.

This paper is organized as follows: first, the alliance portfolio diversity literature is reviewed. I then propose a framework to resolve the current debate in alliance portfolio research - whether the relationship between alliance portfolio diversity and performance is positive or negative. Following the firm diversification literature, I will (1) distinguish related alliance portfolio diversity from unrelated alliance portfolio diversity, and (2) apply dominant logic theory to argue that the direction and value of a firm's alliance portfolio diversity depends in part on that firm's dominant logic(s). I submit that when the firm matches its alliance portfolio diversity strategy to its dominant logic(s), it will experience greater performance. Next, I will argue that if firms engage in alliance portfolio diversity in an sector(s) that does not match its dominant logic(s), there will be a mismatch, triggering a reduction in firm performance and the development of a new dominant logic. Finally, I offer directions for future research.

\section{LITERATURE REVIEW}


Alliance portfolio diversity has been the focus of many modern studies in the strategic management literature (Lee et al., 2017). Although the impact of alliance portfolio diversity on performance has received much attention (e.g., Goerzen \& Beamish, 2005, Jiang et al., 2010; Lee et al., 2014; Ozcan \& Eisenhardt, 2009; Wuyts \& Dutta, 2014), the results are mixed (Lee et al., 2017; Wuyts \& Dutta, 2014). A recent meta-analysis found that the direction of the results depend on the specific theory used and the specific type of alliance portfolio diversity measured (e.g., industry, geographic, etc.; Lee et al., 2014). Indeed, papers that employ transaction cost economics and focus on the costs of diversity are likely to report a negative relationship between alliance portfolio diversity and performance, whereas papers that employ the resource based view and focus on the resource or learning benefits of diversity are more likely to report a positive relationship (Lee et al., 2014).

Although alliance portfolio diversity is an important construct, it is theoretically complicated (Lee et al., 2014). Thus, it is warranted to decompose alliance portfolio diversity into separate dimensions to help make sense of the alliance portfolio diversity and firm performance relationship. To decompose alliance portfolio diversity, it may be useful to first consider the process used by management scholars to decompose firm diversification. The firm diversification literature separates firm diversification into related diversification and unrelated diversification dimensions, which together equal total firm diversification (e.g., Bettis, 1981; Palepu, 1985; Rumelt, 1974).

Prahalad and Bettis (1986:499) define related diversification as the "strategic similarities of [a firm's] businesses and the cognitive composition of the top management team." Thus, related diversification considers similarities in markets, industries, and technologies (Grant, 1988). The distinction between related and unrelated firm diversification is important; related firm diversification leads to greater profitability than unrelated firm diversification (Rumelt, 1974). Similarly, Bettis (1981) found that firms employing related diversification outperform firms that employ unrelated diversification. Related diversification allows companies to exploit their core factors, enjoying economies of scale, more efficient resource allocation, and the ability to exploit technical and managerial skills (Palepu, 1985). Related diversification also allows managers to draw from schemas to inform decisions. Unrelated diversification, on the other hand, offers fewer operating synergies, and is unlikely to positively affect performance unless the unrelated diversifier can achieve significant market power (Palepu, 1985).

Following prior research on schemas and mental maps, Prahalad and Bettis (1986) theorized that managers face limits on the diversification levels that can be 
managed by schemas, developed from managers' interpretations of past experiences. The schemas serve as a mental road map, which become part of the organization's culture (Ginsberg, 1989). Schemas are shared among the top management team as a dominant logic (Prahalad \& Bettis, 1986). Put differently, a dominant logic is a common way for managers to view their business and allocate resources, manifested in the expectations and assumptions managers hold about a particular business context (Kor \& Mesko, 2013).

A dominant logic allows diversified firms to create a framework that guides their business units without requiring the top management team to make specific strategic decisions in each unit (Lampel \& Shamsie, 2000). In using a dominant logic, organizations sustain their current strategy and typically perform well at their current tasks (Prahalad, 2004). Therefore, a dominant logic translates the firm's top management team's capabilities into competencies within a given business (Kor \& Mesko, 2013). Strategically similar forms of diversification (i.e., related) may then be grouped into sectors and managed by a single dominant logic (Prahalad \& Bettis, 1986). As firms enter new businesses, they must add additional dominant logics; "diversified firms, with strategic variety, impose the need for multiple dominant logics (Prahalad \& Bettis, 1986:490)." Additional dominant logics must then be carefully developed and supported by the top management team (Lampel \& Shamsie, 2000), which then requires the ability to simultaneously process multiple dominant logics (Prahalad \& Bettis, 1986).

Ultimately, an established dominant logic influences the direction and extent to which a firm will innovate and grow (Kor \& Mesko, 2013). For example, the international experiences of individual members of the top management team may lead to a framework that directs a business unit's international diversification (Sambharya, 1996; Tihanyi, Ellstrand, Daily, \& Dalton, 2000). Indeed, research supports the notion that firms are more likely to benefit from diversification that matches the firm's dominant logic. Continuing our example, if the international experience of the top management team is concentrated in a particular geographic region, the firm is likely to diversify into that region (Tihanyi et al., 2000). Similarly, as a firm gains foreign partnering experience, adding additional foreign partners leads to increases in firm performance (Lavie \& Miller, 2008). In short, a firm should only add an international alliance partner to its portfolio when doing so is consistent with the firm's dominant logic. In other words, the firm can enjoy an economy of scale from its dominant logic as it engages related diversification that matches the logic. When the firm's dominant logic indicates that diversifying would be optimal, the firm should realize an increase in performance from doing so (Prahalad \& Bettis, 
1986).

In sum, dominant logic theory explains why related firm diversification, on average, leads to better results than unrelated firm diversification. A firm can develop a specialization in a certain sector, and therefore a dominant logic. The organization may then spread resources, skills, and other core factors across the sector of related businesses. In the next section, I will consider how the same process used to help untangle the impact of firm diversity on performance can be used in the alliance portfolio context.

\section{THEORETICAL DEVELOPMENT}

Above, I restated the value in distinguishing between related firm diversification and unrelated firm diversification, and reviewed the reasons why, on average, related firm diversification leads to higher profitability than unrelated firm diversification. Dominant logic theory explains, in part, how firms can capitalize on related diversification. I will now shift the discussion to the alliance portfolio context. Alliance portfolios sometimes include overlapping partners that conduct related transactions (Wassmer, 2010). On the other hand, alliance portfolios sometimes include partners that share very few similarities (Goerzen \& Beamish, 2005). Because the firm diversity literature suggests that the two different types of diversity have important managerial and performance consequences, I submit that it is important to decompose alliance portfolio diversity; the distinction may help explain variation in outcomes such as performance.

When managers form multiple alliances with partners from the same industry (i.e., related alliances), they are more likely to build high performing portfolios (e.g., Ozcan \& Eisenhardt, 2009). Henceforth, I use the term 'related alliance portfolio diversity' to refer the degree that a firm's alliance portfolio contains alliances that share similarities along one or more dimensions of diversity (e.g., there are multiple alliances located in a particular geographic region). I conceptualize related alliances distinct from horizontal alliances, which is any alliance the focal firm forms that belongs to the same industry as the focal firm (c.f., Chan, Kensinger, Keown, \& Martin, 1997). Related alliance portfolio diversity serves several purposes - it allows faster learning (c.f. Baum et al., 2000; Draulans, Deman, \& Volberda, 2003), reduces any one alliance partner's bargaining power (c.f. Ozcan \& Eisenhardt, 2009), supports network resource exchange (c.f. Lavie \& Miller, 2008), and allows a complete transaction to split among alliance partners who may each complete segments of the overall transaction (Wassmer, 2010). This may be beneficial, in that 
similarities across alliances may offer managers opportunities to create synergies (Ozcan \& Eisenhardt, 2009) and a higher potential for learning (Jiang et al., 2010).

I conceptualize 'unrelated alliance portfolio diversity' to refer to the degree that a firm's alliance portfolio contains alliances that do not share similarities. Theory suggests that there may be certain environments where unrelated alliance portfolio diversity would be advantageous. Indeed, unrelated alliance portfolio may allow managers to reduce uncertainty, develop skills and resources, and exploit market power (Goerzen \& Beamish, 2005). As noted earlier, maintaining a small alliance portfolio with diverse (i.e., unrelated) partners may offer managers better access to a wider range of resources, information, and capabilities than a larger alliance portfolio with related partners. In practice, however, it is often difficult to realize such benefits from unrelated alliance portfolio diversity (Goerzen \& Beamish, 2005; Inkpen \& Beamish, 1997).

Despite the possible benefits (and costs) of alliance portfolio diversity, the alliance portfolio diversity literature finds that differences exist between firms that employ the same - or very similar - levels of alliance portfolio diversity (e.g., Lee et al., 2017). Thus, theoretically, it is unknown whether related alliance portfolio diversity necessarily results in better performance as it does in the firm diversity context. Consequently, dominant logic theory may be useful to help explain which type of alliance portfolio diversity may be most beneficial. Accordingly, the correct type of alliance portfolio diversity depends on the firm's dominant logic(s).

Extensiveness of APD. As discussed earlier, a dominant logic is the manifestation of the beliefs, assumptions, and intentions of the CEO and top management (Kor \& Mesko, 2013; Lampel \& Shamsie, 2000). Accordingly, a firm's dominant logic extends beyond the managerial level and influences firmlevel properties such as knowledge, capabilities, and resource commitments (Kor \& Mesko, 2013). Strategically similar forms of diversification may be grouped into sectors (Prahalad \& Bettis, 1986). Thus, in shifting the focus to the alliance portfolio level, managers may benefit from a dominant logic by holding the ability to leverage an extensive knowledge base across an entire sector of related alliances. Indeed, a dominant $\operatorname{logic}(\mathrm{s})$ that matches a related alliance sector is beneficial because managers can draw from their extensive knowledge bases, capabilities, and resources (Prahalad \& Bettis, 1986).

Learning presents one of the greatest advantages for engaging related alliance portfolio diversity when it matches the firm's dominant logic(s). There is evidence that increased similarity between the focal firm and its alliance portfolio increases organizational learning (e.g., Lane \& Lubatkin, 1998). I propose that (1) 
a firm is more likely to learn - and thus improve the firm's dominant logic(s) when it maintains a related alliance sector that matches the firm's dominant logic(s), and (2) the firm's dominant logic(s) allows managers to more effectively manage alliance portfolio diversity that matches the dominant logic(s). Consider the case of absorptive capacity, which is defined as a firm's ability to recognize, assimilate, and apply external information (Cohen \& Levinthal, 1990). By engaging in related alliance portfolio diversity that matches the firm's dominant logic(s), managers can maximize absorptive capacity, or the likelihood that it will recognize, assimilate, and apply the new knowledge. Thus, a firm may be able to enjoy learning-based economies of scale across the related alliance sector.

The schemas and assumptions that together comprise the firm's dominant logic are encoded in the organization's routines (Kor \& Mesko, 2013); a prominent dominant logic encourages management to make decisions consistent with the logic (Kor \& Mesko, 2013). Forming additional (related) alliances in the sector(s) that match the firm's dominant logic(s) would be one such action that is consistent with the firm's dominant logic. While a dominant logic(s) creates learning-based economies of scale that reduces the costs and complexity of adding additional (related) alliances, the firm's dominant logic(s) also directs managers' attention away from forming alliances with partners in sectors that do not match the firm's dominant logic(s). Indeed, a dominant logic functions as an information filter that rejects unneeded and unwanted information (Bettis \& Prahalad, 1995; Kor \& Mesko, 2013), allowing managers to focus their attention on relevant information that does match the firm's dominant logic(s) (Kor \& Mesko, 2013). Prahalad (2004) suggests that dominant logics limit a firm's peripheral vision. Therefore, it is little surprise that Reuer, Park, and Zollo (2002) found that when managers have very homogeneous alliance experience, it was difficult to benefit from that experience when they added dissimilar alliances to the portfolio. When the firm forms alliances in many different sectors (i.e., unrelated alliances), it must maintain different vocabularies, paradigms, and objectives (Goerzen \& Beamish, 2005). Therefore, a prominent dominant logic(s) reduces the ability of the firm to pursue unrelated alliance portfolio diversity because the very information that managers are likely to reject is, by definition, necessary for unrelated alliance portfolio diversity.

Therefore, I expect that as the prominence of the firm's dominant logic increases, firms will engage more extensively in related alliance portfolio diversity in sectors that match the firm's dominant logic(s), and will engage less extensively in unrelated alliance portfolio diversity. Stated formally: 
Proposition 1a: As the prominence of a firm 's dominant logic(s) increases, it will engage more extensively in related alliance portfolio diversity in sectors that match its dominant logic(s).

Proposition 1b: As the prominence of a firm's dominant logic(s) increases, it will engage less extensively in unrelated alliance portfolio diversity

Although firms can benefit from maintaining a prominent dominant logic(s), it is possible that certain firms may lack prominent logics(s). Using a case of a small company operating in a remote village, Prahalad (2004) acknowledges this possibility. Prahalad (2004:178) offers that the "lack of an old and deeply entrenched dominant logic gives them a tremendous advantage in seeing the opportunities of these peripheral markets." Indeed, maintaining more dissimilar alliance partners could be advantageous in that they offer managers a chance to develop more capabilities at a lower cost than instead maintaining alliances with similar partners (Baum et al., 2000). Thus, I submit that forming alliances in peripheral markets will give managers more general alliance management skills, in turn an alliance management capability (c.f., Reuer et al., 2002; Wassmer, 2010). Given that managers are more motivated to diversify internationally when their shared mindset has a worldwide outlook (Sambharya, 1996), I similarly expect that the existence of an alliance management capability will motivate managers to continue seeking partners in peripheral markets when there is a benefit to do so.

Lacking a prominent dominant logic, managers may forge alliances with companies in these peripheral markets for reasons other than learning, such as real options (e.g., Vassolo, Anand, \& Folta, 2004). According to real options theory, firms may elect to form alliances in peripheral markets to discover new opportunities, thereby creating an option in the future to acquire the alliance partner if uncertainty around those opportunities is reduced (Vassolo et al., 2004). In sum, I expect that firms lacking a prominent dominant logic(s) will engage in higher levels of unrelated alliance portfolio diversity, and lower levels of related alliance portfolio diversity. Stated formally:

Proposition 2a: As the prominence of a firm's dominant logic(s) decreases, it will engage more extensively in unrelated alliance portfolio diversity

Proposition 2b: As the prominence of a firm's dominant logic(s) decreases, it will engage less extensively in related alliance portfolio diversity in sectors 
that match its dominant logic(s).

Performance of APD. The price to create a possible real option, however, is high. Indeed, unrelated alliance portfolio diversity is difficult to manage, and it is often a challenge for firms to realize any benefits from such activities (Goerzen \& Beamish, 2005; Inkpen \& Beamish, 1997). Indeed, as firms become more diverse and introduce new businesses, there is a loss in corporate focus that leads to higher costs and higher chances of resource misallocation (Goerzen \& Beamish, 2005). Indeed, due to cognitive limits on how much new information they can handle, in dissimilar industries, managers face difficulty identifying and selecting the best partners, and monitoring partners' actions (Vasudeva \& Anand, 2011). In sum, managers are unlikely to make the correct changes when the firm's dominant logic does not match a given situation (Prahalad \& Bettis, 1986).

Engaging in related alliance portfolio diversity that matches the firm's dominant logic(s), on the other hand, allows managers to apply their schemas and experiences, resulting in greater efficiency and the ability to respond quickly to environmental changes (Prahalad \& Bettis, 1986). In the case for firms with multiple dominant logics that maintain firm diversification in multiple sectors, managers only need to update the logic that matches the industry undergoing change (c.f., Prahalad \& Bettis, 1986). Generally speaking, when firms increase the efficiency of their alliance portfolios, they realize greater performance (e.g., Jiang et al., 2010; Lee et al., 2017; Wassmer, 2010). Thus, because I expect a dominant logic(s) to reduce the complexity and difficulty of managing related alliance portfolio diversity, managers should experience greater performance when they engage in related alliance portfolio diversity that matches a prominent dominant logic.

Thus, I expect that related alliance portfolio diversity is more likely to be successful when it matches the firm's dominant logic(s). Stated formally:

Proposition 3: Firms will experience greater performance as they increase related alliance portfolio diversity in a sector(s) that matches its dominant $\operatorname{logic}(s)$

A mismatch could occur if a dominant $\operatorname{logic}(\mathrm{s})$ is present in the top management team, and (1) the firm pursues unrelated alliance portfolio diversity, or (2) the firm pursues related alliance portfolio diversity in a sector that does not match the firm's dominant logic(s). I propose that either scenario would be problematic because it ignores the dominant logic(s), and may lead to a lack of focus. It would 
therefore lead to a higher likelihood that managers will make suboptimal decisions. Indeed, managers often apply dominant logics to new businesses, even when the new businesses do not match the firm's dominant logic(s) (Prahalad \& Bettis, 1986). Thus, Prahalad (2004) acknowledges that a dominant logic will hinder diversity outside the sector of the logic. Ultimately, Goerzen and Beamish (2005) suggest that such alliance portfolio diversity could harm firm performance, because the (unrelated) alliance portfolio diversity's administrative burden, inefficient resource allocations, and possibility for errors lead to increased costs.

To eventually benefit from diversity in sectors it lacks a dominant logic, the firm will need to change its dominant logic, or develop a dominant logic in the new sector (Prahalad \& Bettis, 1986). However, it may be very difficult and costly to change a dominant logic for several reasons (Prahalad, 2004). First, changing a dominant logic usually first requires some type of crisis whereby the firm's survival is dependent on finding a new logic (Prahalad \& Bettis, 1986). Then, before strategic learning of any kind can occur, firms need to "unlearn" the old dominant logic (Bettis $\&$ Prahalad, 1995). Through unlearning, managers purge old logics and behaviors to allow room for the new logic (Bettis \& Prahalad, 1986). Bettis and Prahalad (1986) describe the process of changing a dominant logic, which involves (1) adding individuals with significantly different experiences to the top management team, (2) encouraging managers to take sabbaticals and educational experiences to enrich their experiences, (3) rehearsing for scenarios the firm may encounter in the future, (4) changing managerial evaluations so that managers are not punished for failed experiments, and (5) allowing dissent. Alternatively, an organization may retain the old dominant logic and add a new one. The process of adding a new logic, however, requires a firm to develop the ability to simultaneously handle multiple logics (Prahalad \& Bettis, 1986).

Thus, when managers engage related alliance portfolio diversity in sectors in which it lacks a dominant logic, they are likely to suffer in efficiency and environmental awareness as the existing logic is based on knowledge that is inappropriate for the new sector. In turn, I expect these firms will experience a decrease in firm performance. To overcome the decrease in firm performance, the firm must then change its existing logic or add a new one. Stated formally:

Proposition 4: Firms that engage in related alliance portfolio diversity in sectors it lacks a dominant logic (i.e., a mismatch) will experience decreased performance 
Proposition 5: Firms that engage in related alliance portfolio diversity in sectors it lacks a dominant logic (i.e., a mismatch) will develop a dominant logic in that sector.

\section{$\overline{\text { DISCUSSION }}$}

This framework offers a perspective that describes why certain firms are better able to handle - and thus experience greater performance from -- alliance portfolio diversity (e.g., Jiang et al., 2010; Lee et al., 2017). My paper is the first to distinguish related alliance portfolio diversity from unrelated alliance portfolio diversity. I propose that when managers match alliance portfolio diversity to the firm's dominant logic(s), they will experience greater operational synergies, learning opportunities, and performance. When managers do not engage the appropriate form of alliance portfolio diversity given the firm's dominant logic(s), performance suffers, and the firm will need to either add a new dominant logic or change the existing logic.

This study has several key implications for alliance portfolio research. One, I argue that the remedy to the elusive link between alliance portfolio diversity and firm performance may be found by considering dominant logic theory. The present paper explores the idea that (1) it is important to distinguish related alliance portfolio diversity from unrelated alliance portfolio diversity, and (2) that firms with a single (multiple) dominant logic(s) are suited to engage and benefit from greater alliance portfolio diversity in the sector(s) matching the firm's dominant logic(s).

Future empirical research would be useful to test the propositions put forth in this paper. In particular, qualitative research would be beneficial in that such research could more fully consider the many compromises managers face in adding alliances that do not match the firm's dominant logic(s). Alternatively, an archival based approach could be executed. An archival based approach could measure the firm's dominant logics by coding the experiences and backgrounds of the top management team. Data needed to compute related alliance portfolio diversity and unrelated alliance portfolio diversity could be created by first coding alliance announcements, then utilizing the calculation of related and unrelated firm diversification developed by Palepu (1985). As Lee et al. (2017) find, the specific measure of performance may influence findings. Thus, future researchers should include a broad perspective of performance measures, spanning economic, innovative, and market-based performance measures. Future research may also 
consider moderators on the relationship between related alliance portfolio diversity that matches the dominant logic and performance. As Lee et al. (2017) find, the type of theory used may influence the relationship. In addition, there may be other industrial and environmental moderators that may influence performance.

I submit that researchers and practitioners should be able to predict the type of alliance portfolio diversity firms will engage by exploring the structure (i.e., the firm's dominant logic[s]). Practitioners are advised to consider the increased learning and synergistic opportunities created by matching alliance portfolio diversity to an existing dominant logic, and the possible signaling effect that adding a new dominant logic will create. For managers, the present paper points to the possibility that early decisions made by the firm, such as whom to include in the top management team, may impact future strategic decisions such as the optimal choice of alliance partners. The firm's dominant logic likely affects other alliance level processes, such as alliance management capabilities, coordination across multiple alliances, and the potential to realize innovation (e.g., Cui \& O'Connor, 2012). Thus, future alliance portfolio research should control for the effect of top management team level characteristics. Managers should also be advised that diversifying into new businesses where it lacks a dominant logic may lead to negative performance and the need to revise or develop an appropriate logic. Consider the case of Euro Disney, itself formed as an alliance between Disney and the Kingdom Holding Company. In expanding to a new region, Disney initially applied its dominant logic, gained from many years of experience operating Disneyland in California, where alcohol was forbidden inside the theme park. Disney's dominant logic led the company to ignore the French culture, where sipping wine in boulevard spanning patios is commonplace. Disney acknowledged prohibiting alcohol was a mistake, taking corrective action that allowed wine to be served in its French theme park. It spent effort learning the French culture, thereby adding a new logic.

Future research should consider alternative explanations for the varied relationships found between alliance portfolio diversity and performance, such as the role of the environment and transaction costs (e.g., Goerzen \& Beamish, 2005). More attention should be given to the role of capabilities, which was previously thought of exclusively as a generalized alliance management skill that would apply to each alliance present on the portfolio (e.g., Baum et al., 2000). However, dominant logic theory holds that the appropriate capability depends on the specific sector of diversity. Therefore, the firm's skill in managing alliances located in a specific industry may not necessarily transfer to other industries. Future work would be useful to delineate the need for specialized versus general alliance portfolio knowledge. 


\section{CONCLUSION}

The present paper reinforces the notion that managers are more careful and purposeful about the level of alliance portfolio diversity employed. I posit that when there is a prominent dominant logic, managers will select related alliance portfolio diversity that matches the firm's dominant logic(s), and it will perform well for doing so. When a firm lacks a prominent dominant logic, they will engage in unrelated alliance portfolio diversity. If a firm pursues related alliance portfolio diversity in a sector that does not match its dominant logic, it will experience a decrease in performance and must develop a dominant logic in the new sector.

It is my hope that this paper establishes a framework to settle the on-going debate in the alliance portfolio diversity literature. Future research on alliance portfolio diversity could benefit by drawing more from the firm diversification literature, where dominant logic theory was used to reconcile a similar debate. Instead of searching for a blanket statement that definitively states whether alliance portfolio diversity increases or decreases firm performance, I strongly suggest that alliance portfolio researchers accept that the answer is "it depends", and begin to identify other boundary conditions that determine when alliance portfolio diversity will improve firm performance.

\section{REFERENCES}

Bamford, J., \& Ernst, D. (2002). Managing an alliance portfolio. The McKinsey Quarterly, 3: 29-39.

Baum, J., Calabrese, T., \& Silverman, B. (2000). Don't go it alone: Alliance network composition and startups' performance in Canadian biotechnology. Strategic Management Journal, 21: 267-294.

Bettis, R. (1981). Performance Differences in Related and Unrelated Diversified Firms. Strategic Management Journal, 2:379-393.

Bettis, R., \& Prahalad, C. (1995). The Dominant Logic: Retrospective and Extension. Strategic Management Journal, 16: 5-14.

Chan, S., Kensinger, J., Keown, A., \& Martin, J. (1997). Do strategic alliances create value? Journal of Financial Economics, 46: 199-221.

Cohen, W., \& Levinthal, D. (1990). Absorptive capacity: A new perspective on learning and innovation. Administrative Science Quarterly, 35:182-152.

Cui, A., \& O'Connor, G. (2012). Alliance portfolio resource diversity and firm innovation. Journal of Marketing, 76(4), 24-43. 
Das, T., \& Teng, B. (2000). A resource-based theory of strategic alliances. Journal of Management, 26: 31.

Draulans, J., Deman, A, \& Volberda, H. (2003). Building alliance capability: Management techniques for superior alliance performance. Long Range Planning, 36: 151-166.

Dussauge, P., Garrette, B., \& Mitchell, W. (2000). Learning from competing partners: outcomes and durations of scale and link alliances in Europe, North America and Asia. Strategic Management Journal, 21, 99-126.

Ginsberg, A. (1989). Construing the business portfolio: a cognitive model of diversification. Journal of Management Studies, 26: 417-38

Goerzen, A., \& Beamish, P. (2005). The effect of alliance network diversity on multinational enterprise performance. Strategic Management Journal, 26: 333-354.

Grant, R. (1988). On 'Dominant Logic', Relatedness, and the Link Between Diversity and Performance. Strategic Management Journal, 9: 639-642.

Hoffmann, W. (2005). How to manage a portfolio of alliances. Long Range Planning, 38(2): 121-143.

Hoffmann, W. (2007). Strategies for managing a portfolio of alliances. Strategic Management Journal, 28: 827.

Inkpen A, Beamish P. (1997). Knowledge, bargaining power, and international joint venture stability. Academy of Management Review 22: 177-202.

Jiang, R., Tao, Q., \& Santoro, M. (2010). Alliance portfolio diversity and firm performance. Strategic Management Journal, 31(10), 1136-1144.

Kale, P., \& Singh, H. (2009). Managing strategic alliances: What do we know now, and where do we go from here? The Academy of Management Perspectives, 23: 45-62.

Kor, Y., \& Mesko, A. (2013). Dynamic managerial capabilities: Configuration and orchestration of top executives' capabilities and the firm's dominant logic. Strategic Management Journal, 34(2), 233-244.

Lampel, J., \& Shamsie, J. (2000). Probing the Unobtrusive Link: Dominant Logic and The Design of Joint Ventures at General Electric. Strategic Management Journal, J., 21: 593-602

Lane, P.J., \& Lubatkin, M.(1998). Relative absorptive capacity and interorganizational learning. Strategic Management Journal, 19:461-477.

Lavie, D., \& Miller, S. (2008). Alliance portfolio internationalization and firm performance. Organization Science, 19: 623-646.

Lee, D., Kirkpatrick-Husk, K., \& Madhavan, R. (2017). Diversity in Alliance Portfolios and Performance Outcomes: A Meta Analysis. Journal of Management. 
Ozcan, P., \& Eisenhardt, K. M. (2009). Origin of alliance portfolios: Entrepreneurs, network strategies, and firm performance. Academy of Management Journal, 52: 246-279.

Palepu, K. (1985). Diversification strategy, profit performance and the entropy measure. Strategic Management Journal, 6(3), 239-255.

Prahalad, C. (2004). The Blinders of Dominant Logic. Long Range Planning, 37:171-179.

Prahalad, C., \& Bettis, R. (1986). The Dominant Logic: a New Linkage Between Diversity and Performance. Strategic Management Journal, 7: 485-506.

Reuer, J., Park, K., \& Zollo, M. (2002). Experiential learning in international joint ventures: The roles of experience heterogeneity and venture novelty, in F.J. Contractor and P. Lorange (eds.) Cooperative Strategies and Alliances, 321344. Oxford, UK: Pergamon - Elsevier Science.

Rumelt, R. (1974). Strategy, Structure and Economic Performance, Harvard University Press, Cambridge, MA.

Tihanyi, L., Ellstrand, A., Daily, C., \& Dalton, D. (2000). Composition of the Top Management Team and Firm International Diversification. Journal of Management, 26: 1157-1177.

Sambharya, R. (1996). Foreign experience of top management teams and international diversification strategies of US multinational corporations. Strategic Management Journal, 17: 739-746.

Vassolo, R., Anand, J., \& Folta, T. (2004). Non-additivity in portfolios of exploration activities: A real options- based analysis of equity alliances in biotechnology. Strategic Management Journal, 25: 1045-1061.

Vasudeva, G., \& Anand, J. (2011). Unpacking absorptive capacity: A study of knowledge utilization from alliance portfolios. Academy of Management Journal, 54, 611-623

Wassmer, U. (2010). Alliance portfolios: A review and research agenda. Journal of Management, 36: 141-171.

Wuyts, S., \& Dutta, S. (2014). Benefiting from alliance portfolio diversity: The role of past internal knowledge creation strategy. Journal of Management, 40(6), 1653-1674. 


\section{BIOGRAPHICAL SKETCH OF AUTHOR}

Dr. Christopher Penney is an Assistant Professor of Management at the University of North Texas in Denton, TX. Dr. Penney earned his PhD from Florida State University. His research focuses on alliance portfolios, cooperative strategy, family businesses, transaction cost economics, and firm diversification. 